\title{
Epidemiological and Clinical Factors Impact on Survival in ALS/MND: a Cohort Study
}

\author{
Francis Meire Favero', Mariana Callil Voos² \\ Luiz Carlos de $\mathrm{Abreu}^{3}$, Isac de Castro ${ }^{4}$, \\ Fátima Aparecida Caromano ${ }^{2}$ \\ Abrahão Augusto Juviniano Quadros ${ }^{1}$, \\ Sissy Veloso Fontes ${ }^{1}$, Acary Souza Bullé Oliveira ${ }^{1}$
}

\section{Abstract}

Background: Motor neuron diseases (MND) are rare yet severe neurodegenerative disorders with peculiar characteristics of unknown etiologies that cannot be prevented. They are irreversible and incurable, but treatable diseases. Treatment can improve the quality of life and increase survival. This study aimed to investigate the impact of epidemiological and clinical factors in individuals with motor neuron diseases, particularly amyotrophic lateral sclerosis (ALS). This study aimed to analyse the survival of patients with ALS in relation to clinical and epidemiological aspects.

Methods: Data were collected from charts in the Division of Clinical Investigation on Neuromuscular Diseases (DCINM), (from 1999 to 2011). Kaplan-Meier curves illustrated the survival time.

Results: A total of 1146 records of patients with MND were investigated and 578 records, in accordance with the inclusion criteria, were included. For analyzing epidemiological and clinical aspects 231 records were included and survival curves were plotted.

Conclusion: The survival of patients with MND was not influenced by sex. Younger patients live longer. Too much time passes between initial symptoms and $1^{\text {st }}$ appointment. Patients who survive longest are those who were not diagnosed on the 1st appointment, or did not show any clinical and electromyographic findings, and presented with initial symptoms in the lower limbs.
1 Department of Neurology/Neurosurgery -UNIFESP, São Paulo- SP, Brazil.

2 Department of Physical Therapy, Speech and Occupational Therapy, FMUSP, São Paulo- SP, Brazil.

3 Department of Health Collective/Scientific Methodology of Discipline -ABC Medical, Santo André-SP, Brazil.

4 Department of Nephrology, FMUSP, São Paulo- SP, Brazil.

\section{Contact information:}

Luiz Carlos de Abreu.

Laboratório de Delineamento de Estudos e Escrita Científica. Departamento de Saúde da Coletividade. Disciplina de Metodologia Científica.

Address: Faculdade de Medicina do ABC. Santo André, SP. Brasil. Av. Príncipe de Gales, 821, Santo André, SP CEP 09060-650.

Đl luiz.abreu@fmabc.br

Keywords

epidemiology;

amyotrophic lateral sclerosis; motor neuron disease; survival. 


\section{Introduction}

The motor neuron diseases (MND) are a group of neurodegenerative disorders that predominantly affect the motor system. Among them include progressive muscular atrophy (PMA) that attacks lower motor neurons (LMN); progressive bulbar palsy (PBP), which causes upper motor neuron (UMN) lesions as well as lower; primary lateral sclerosis (PLS), encompassing only UMN injury; and amyotrophic lateral sclerosis (ALS), which results from the combined degeneration of UMN and LMN [1, 2].

Clinically characterized by weakness, hyperreflexia, and spasticity when there is involvement of the UMN and twitching, atrophy, weakness, and hyporeflexia when there is involvement of the LMN, MNDs are classified according to the site of primary involvement of motor neurons, the morphological changes, the inheritance pattern and electrophysiological findings. Its evolution can compromise all members, including the bulbar muscles. The survival of patients with these disorders is low and may vary depending on the initial involvement of the neuromuscular system [3].

The epidemiological studies, clinical studies, and especially the experiments with animal models lead to the conclusion that ALS/MND disease is related to the presence of some genetic factor [4-5]. The clinical expression of symptoms could be related to a genetic predisposition in such patients, who have a genetic marker for some factor or factors that incites a cascade of neurotoxic activities, triggering the motor neuron degeneration process activated in special situations. Among the triggers, we highlight endogenous factors, such as inflammation and mitochondrial, systemic or exogenous changes, such as exposure to toxic agents, strenuous activities, and intake of food and medicine [4-16].

The diagnosis of ALS is currently related to the history and progression of the disease, with evidence of the involvement of UMN and LMN [17], according to the criteria of El Escorial [18]. To determine the involvement of the LMN physicians use electromyography (EMG) that assesses the degree of impaired nerve conduction velocity in motor fibers [19-20]. It is difficult, however, to detect the involvement of UMN, as there are often only mild impairment signals, which can generate questions for the definitive diagnosis of ALS and the need to rule out other diseases [17, 20-22].

There is interest in understanding pathophysiology of ALS/MND. Research conducted in recent years has shown that ALS/MND is not a disease with a single cause. There are no doubts that ALS/ MND is clinically and biologically a heterogeneous neurological disorder. The recognition of this heterogeneity is important, especially when proposing to carry out clinical trials, which may not work for most, but can help some patients. This opens a rare opportunity to target etiopathogenic aspects of the disease, seeking therapeutic interventions that can increase patient survival rates. Today, we seek not just to know more about the causes of these diseases but also what can be used as a protective factor [23].

\section{Objective}

To analyze the survival of patients with amyotrophic lateral sclerosis/ motor neuron diseases (ALS/ MND) in relation to clinical and epidemiological aspects.

\section{Methods}

This is a prospective cohort study. It has been approved by the Ethics Comittee of Federal University of São Paulo. During the 12-year study-period (from 1999-2011), we identified patients from the Motor Neuron Disease Clinic from the Division of Clinical Investigation on Neuromuscular Diseases (DCINM) [24], Department of Neurology and Neurosurgery of the Federal University of São Paulo. These patients had received an ALS diagnosis, according to 
the criteria of El Escorial from the World Federation of Neurology (World Federation of Neurology Research Group on Neuromuscular Diseases).

The 1146 patients with MND were analyzed. Almost half, or 568 (49.56\%) patient records were excluded because they had not received a definite diagnosis of ALS/MND or they were incomplete because either the patient had been in the process of assessment and the record did not contain all required information or certain questions had not been answered by the patient or their primary caregiver. We included all 578 (50.43\%) records that contained the confirmed diagnosis of ALS/MND according to revised criteria of El Escorial World Federation of Neurology [25]. The tabulated data records for the analysis of the study were taken from a total of 231 patients who had died, featuring

- epidemiological aspects: age, sex, and skin color

- pathophysiological symptoms: classification and form of MND

- clinical aspects: time of diagnosis, whether the diagnosis had been made before or after the first visit to the DCINM, the initial topography of clinical impairment, and the presence of electromyography in first appointment in DCINM

- therapeutic aspects, such as pre-consultation time: time between the initial symptom of disease until the 1st. DCINM appointment

- diagnostic time: period of time from the first appointment date at DCINM until diagnosis

- dwell time: the time period from the first DCINM appointment until death

- death: time from diagnosis until death

- total duration of the disease: symptom onset time to death.

\section{Statistical Analysis}

The semi-continuous and continuous data were initially compared to the Gaussian curve by the KS distance and when a nonparametric test were represented by the median and percentiles and compared with results from a Mann-Whitney test. Categorical data were represented by absolute frequency ( $n$ ) and relative frequency (\%).

Survival analysis was performed using the Kaplan-Meier model and the estimated median values if survival was followed by the standard error of estimate. Comparisons between the survival curves were performed by the log-rank test. For all statistical comparisons, we considered the level of significance of $5 \%$. Statistical tests were performed using SPSS 19.0 IBM Corporation.

\section{Results}

For survival analysis, we considered the records of 231 patients who had died during the 12-year study period. The median overall survival period was 10.3 \pm 0.71 months; we set the lower confidence interval (Cl) of $95 \%$ at 9.0 months and an upper $\mathrm{Cl}$ of $95 \%$ at 11.7 months.

In the overall survival curve, we identified that the majority (144 patients) had died before 9 months after their definitive diagnosis, while 87 patients survived beyond 9 months after definitive diagnosis. Considering the lower $\mathrm{Cl}$ 95\% we defined two phases of survival analysis: $<9$ months and $>9$ months.

We defined those with survival $<9$ months as patients with early mortality or with shorter survival and those with mortality $\geq 9$ months with longer survival; therefore, we could establish what factors could be related to the determination of greater or lesser expectation of life in both groups (Figure 1).

Regarding the epidemiological characteristics of the deceased patients $(n=231)$, the median age of the patients analysed $<9$ months was 63 and $\geq 9$ months was 57 years $(p<0.05)$. Males prevailed in $56.1 \%$ (131 patients); the ratio of men to women was 1.32:1 ( $p=0.001)$ (Table 1). As for the color of the skin we found that the white color was most common, accounting for 90\% (209 patients), fo- 
Figure 1: Survival curve of patients with amyotrophic lateral sclerosis/motor neuron disease $(A L S / M N D)$ in time $<9$ months and $\geq$ 9 months.

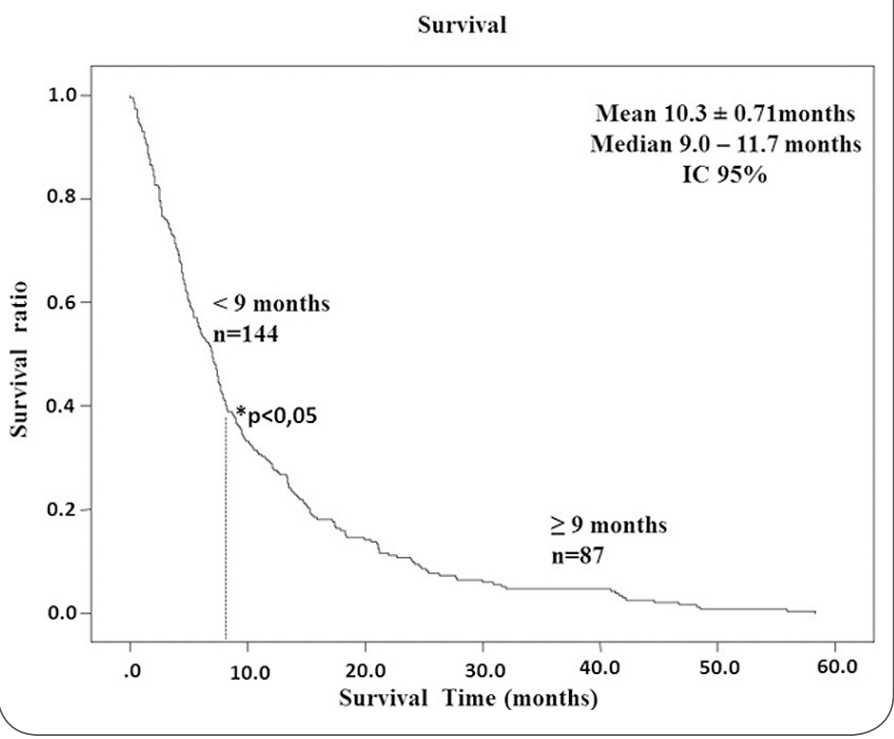

Table 1. Kaplan-Meier curve in patients with survival $<$ and $\geq 9$ months regarding time compared by gender.

\begin{tabular}{|c|c|c|c|c|c|c|c|}
\hline Time & Sex & $n$ & Median & EPM & $\begin{array}{c}95 \% \\
\text { Lower }\end{array}$ & $\begin{array}{l}95 \% \\
\text { Upper }\end{array}$ & Sig. \\
\hline \multirow{3}{*}{$\begin{array}{l}<9 \\
\text { months }\end{array}$} & Female & 63 & 4.1 & 0.74 & 2.66 & 5.54 & \multirow{3}{*}{0.524} \\
\hline & Male & 81 & 4.3 & 0.29 & 3.74 & 4.86 & \\
\hline & General & 144 & 4.2 & 0.25 & 3.71 & 4.7 & \\
\hline \multirow{3}{*}{$\begin{array}{l}\geq 9 \\
\text { months }\end{array}$} & Female & 41 & 15.6 & 2.18 & 11.33 & 19.87 & \multirow{3}{*}{0.241} \\
\hline & Male & 46 & 15.3 & 1.41 & 12.53 & 18.07 & \\
\hline & General & 87 & 15.6 & 1.24 & 13.16 & 18.04 & \\
\hline
\end{tabular}

llowed by the black color in 9\% (19 patients) and $1 \%$ of asian patients (3 patients).

As for MND rating, ALS was the most prevalent $(73.6 \%)$ cases, followed by PBP (21.2\%), PMA (4.3\%) and PLA (0.9\%) (Table 2). Sporadic clinical presentation was found in $100 \%$ of cases.

\section{(Table 3)}

In clinical aspects, patients receiving their diagnosis after the first visit had a higher survival time (21.1 months), compared to 17.4 months of pa-
Table 2. Classification of Motor Neuron Diseases (MND).

\begin{tabular}{|l|c|c|}
\hline \multicolumn{1}{|c|}{ MND Classification } & $\mathbf{n}$ & $\%$ \\
\hline ALS & 170 & 73.6 \\
\hline PBP & 49 & 21.2 \\
\hline PMA & 10 & 4.3 \\
\hline PLA & 02 & 0.9 \\
\hline General & 231 & 100 \\
\hline
\end{tabular}

Table 3. Types of Motor Neuron Diseases (MND).

\begin{tabular}{|l|c|c|}
\hline \multicolumn{1}{|c|}{ Forms of MND } & $\mathbf{n}$ & $\%$ \\
\hline Sporadic & 231 & 100 \\
\hline Family & 0 & 0 \\
\hline General & 231 & 100 \\
\hline
\end{tabular}

tients diagnosed before the first appointment and 13.7 months, of patients diagnosed at the first appointment (Table 4).

Table 4. Kaplan-Meier curve in patients with $\geq$ survival to 9 months as the time of diagnosis.

\begin{tabular}{|c|c|c|c|c|}
\hline Time diagnosis & Median & EPM & $\mathrm{ICI} 95 \%$ & ICS $95 \%$ \\
\hline $\begin{array}{l}\text { Before the 1st } \\
\text { Consultation }\end{array}$ & 17.4 & 1.70 & 14.06 & 20.74 \\
\hline $\begin{array}{l}\text { The 1st } \\
\text { Consultation }\end{array}$ & 13.7 & 0.44 & 12.84 & 14.56 \\
\hline $\begin{array}{l}\text { After the 1st } \\
\text { Consultation }\end{array}$ & $21.1 *$ & 0.20 & 20.71 & 21.49 \\
\hline General & 15.60 & 1.24 & 13.16 & 18.04 \\
\hline
\end{tabular}

As for the correlation with the initial topography of clinical impairment, we observed that the deceased patients who had initial impairment in the lower limbs had longer survival (19.9 months) than those who had initial involvement in the upper limbs (15.6 months) or bulbar region (14.7 months). We observed also that patients who had initial involvement in the upper limbs did not have longer survival than those with bulbar involvement (Figure 2). 
Figure 2: Kaplan-Meier curve in patients with survival $<$ and $\geq$ to nine months as the topography.
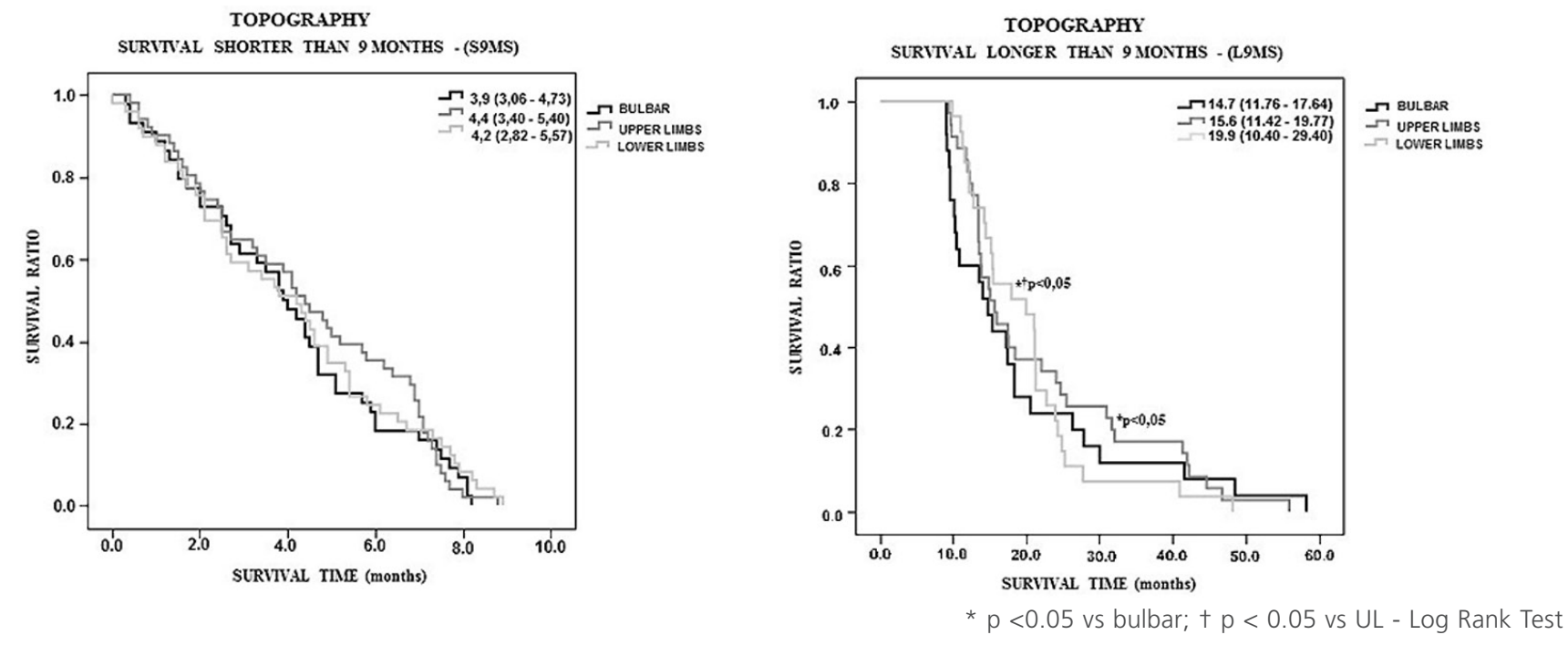

The correlation with electromyography revealed that seven patients had not been submitted to this methodology before the first visit to the DCINM and these had a higher survival rate than those who had previously undergone the examination, both with compatible diagnosis of ALS (15.9 months) and those whose as diagnosis did not mention ALS (14.7 months). Table 5 shows representative data on survival time $\geq$ than 9 months.

Table 5. Kaplan-Meier curve in patients with $\geq$ survival than 9 months measuring electromyography before the first appointment.

\begin{tabular}{|c|c|c|c|c|}
\hline Electromyography & Median & EPM & ICI 95\% & ICS $95 \%$ \\
\hline Not done & 18.4 & . & . & . \\
\hline $\begin{array}{l}\text { Compatible } \\
\text { diagnosis of ALS }\end{array}$ & $15.9 *$ & 1.26 & 13.42 & 18.38 \\
\hline $\begin{array}{l}\text { Diagnosis not } \\
\text { referred to as ALS }\end{array}$ & 14.7 & 1.22 & 12.32 & 17.08 \\
\hline General & 15.6 & 1.24 & 13.16 & 18.04 \\
\hline
\end{tabular}

\section{Discussion}

For survival analysis, we assessed the medical records of 231 patients, who died in the follow-up period of this study. For the deceased who passed away before 9 months elapsed after their diagnostic confirmation, the median age was 63 years, while the median age of the deceased who passed away at the time greater than or equal to 9 months from diagnosis was 57 years old; however, it was not possible to make analysis of survival. However, a retrospective study with 135 patients with ALS/MND in Scotland, describes a difference between young and elderly patients, demonstrating differences in the clinical presentation, survival, and in the process of care [26].

In a mortality study conducted in the city of São Paulo from 2002 to 2006, data on 158 men and 168 women showed no difference between the sexes [27]. However, another study found 127 male patients (56\%) and 104 (44\%) females with a predominance of males, which is in agreement with the Brazilian literature. This fact can be explained by the retrospective time difference studied and causality [28-32].

Regarding skin color, skin was predominantly white in color in the deceased group (90\%). In the work of Matos et al. [27], Dietrich-Neto et al. [29] 
follows the predominant order of white skin color as referred to in this study. Also data from the State System Foundation Data Analysis (SEADE 2004) [33] showed that more than half of the racial composition of the city and metropolitan area of São Paulo is white [33].

Regarding the classification of the disease, $\mathrm{Pa}$ tients with ALS represented $73.6 \%$; this finding is due justification, of the total number of cases of patients with MND, ALS was the most represented (74\%). The sporadic form was recognized in $100 \%$ of deceased patient cases. The rationale is similar to the previous one: looking at the total number of cases of patients with MND, sporadic appears in $95 \%$ of cases. These data are described in the clinical study of patients with MND at UNIFESP [25].

The median survival in clinical trials strongly depends on the characteristics of the population and the inclusion criteria and related exclusions. Because of the many factors that can impact survival, further studies, with epidemiological investigations should be performed, with more homogeneous samples and factors, to comparatively analyse different clinical trials. To avoid registration of subjective data, we consider the time from the date of the defined diagnosis of ALS/MND until the date of death for survival analysis.

Survival analysis, performed using the KaplanMeier curve, enabled us to verify two different time periods: the occurance of death in less than nine months time and death occurring at 9 months or beyond and found a greater number of patients who died (144) in the period of less than 9 months.

Even as the DCINM is a referral center for the care of patients with ALS/MND, many patients evaluated for the first time in DCINM already had very advanced clinical impairment. There was a delay, considered too great between the first symptom and the patient's first query at DCINM, ranging from 9 to 26 months, with a median of 16 months. The delay of diagnosis and the most severe impairment, perhaps, justifies the lowest survival time in this population. Clinical studies $[23,32]$ have shown that survival is lower in patients with major neuromuscular involvement.

In the survival analysis of 231 patients related to gender, there was no significant difference between men and women, but the correlation of survival with age is not demonstrated in this study because it was not possible to set a cut-off point that could define higher or lower risk of death.

Regarding the general monitoring time and survival in months for all patients who died, the statistical difference was related to duration of the disease, which was defined by the date of initial symptoms until the date of death and survival time, referring to the date of diagnosis until the date of death. If both measured longer than nine months, this implies that the patient who died after nine months shows an early condition for the diagnosis of the disease.

Regarding the correlation of survival with the time of diagnosis, there was greater survival difference for patients diagnosed after the first visit to the DCINM, this may have occurred because patients who were not diagnosed during their first visit had a clinical commitment that was mild or less widespread and, therefore, were still under investigation.

As for survival related to the topography of the start of the first symptom, patients presenting with appendicular initial impairment had longer survival, especially those who started with symptoms in the lower limbs. It is believed that the occurring motor neuron involvement affects the proximal cells with a degenerative impairment. Being a disease where there is a spread of clinical manifestations in a contiguous manner, there is a greater time commitment to spinal and bulbar structures that are more related to vital functions (breathing, swallowing), when the initial manifestations are due to lumbosacral marrow involvement $[23,34-36]$. 
We did a survival analysis using the presence or absence of the subsidiary electromyography test (EMG) given at the first visit to the DCINM. Patients who had not been tested before the first appointment had longer survival than those with compatible exams and who were not compatible with a diagnosis of ALS/MND. It can be inferred that this finding is related to the lower neuromotor impairment of these cases and, therefore, doctors who were visited prior to the medical appointment in DCINM, were not considered relevant request ENMG in these cases.

\section{Conclusions}

As for patient survival analysis with ALS/ MND, we find the time period between initial symptoms and the first appointment is too long. There was no significant difference in survival between the sexes.

Long-term survival is associated with younger patients who had no diagnosis defined in the first appointment and who did not present with clinical signs electromyography diagnostics, or onset of symptoms in the lower limbs.

\section{References}

1. Brooks BR. World Federation of Neurology Research Group on Neuromuscular Diseases. El Escorial: World Federation of Neurology criteria for the diagnosis of amyotrophic lateral sclerosis. J. Neurol Sci. 1994; 124 (Suppl 1): 96-107.

2. Swash M, Desai J. Motor Neuron Disease: classification and nomenclature. Amyotrophic Lateral Sclerosis and other Motor Neuron Disorders. 2000; 1: 105-112.

3. Meininger V, Shefner J, Cudkowicz M. Lithium therapy in ALS. Amyotrophic lateral sclerosis: official publication of the World Federation of Neurology Research Group on Motor Neuron Diseases. 2008; 9 (2): 122

4. Rothstein JD. Excitotoxic mechanisms in the pathogenesis of amyotrophic lateral sclerosis. Adv Neurol. 1995; 68: 7-20.

5. Cifra A, Nani F, Nistri A. Eur J Neurosci. Riluzole is a potent drug to protect neonatal rat hypoglossal motoneurons in vitro from excitotoxicity due to glutamate uptake block. 2011 Mar; 33(5).

6. Shaw PJ, Ince PG. Glutamate, excitotoxicity and amyotrophic lateral sclerosis. J Neurol. 1997; 244: Suppl 2: S3-S14.

7. Akhlaq A. Farooqui, Wei-Yi Ong, Lloyd Horrocks. in Neurochemical Aspects of Excitotoxicity. Springer, 2008.

8. Morahan JM, Yu B, Trent Ronald J, Pamphlett R. Genetic susceptibility to environmental toxicants in ALS. American Journal of Medical Genetics. Part B, Neuropsychiatric genetics: the official publication of the International Society of Psychiatric Genetics. 2007; 144B(7): 885-90.

9. Bradley W. New aspects of the cyanobacteria/BMAA hypothesis and future directions. Amyotrophic Lateral Sclerosis.2008; 9 (Suppl1): 40.

10. Chen A, Montes J, Mitsumoto $H$. The role of exercise in amyotrophic lateral sclerosis. Physical medicine and rehabilitation clinics of North America. 2008; 19(3): 545-57.

11. Piazza $O$, Siren $A L$, Ehrenreich $H$. Soccer, neurotrauma and amyotrophic lateral sclerosis: is there a connection? Current Medical Research and Opinion. 2004; 20: (4): 505-508.

12. Armon C. An Evidence-Based Medicine Approach to the Evaluation of the Role of Exogenous Risk Factors in Spopradic Amyotrophic Lateral Sclerosis. Neuroepidemiology. 2003; 22: 217-228.

13. Taioli E. All causes mortality in male professional soccer players. European Journal of Public Health. 2007; 17: (6): 600-604. doi: 10.1093/eurpub/ckm035.

14. Chió A, Traynor BJ, Swingler R, Mitchell D, Hardiman O, Mora $G$, et al. Amyotrophic lateral sclerosis and soccer: a different epidemiological approach strengthen the previous findings. Journal of the Neurological Sciences. 2008; 269(1-2): 187-8; author reply 188-9.

15. Sutedja NA, Veldink JH, Fischer K, Kromhout $H$, Wokke JHJ, Huisman MHB, et al. Lifetime occupation, education, smoking, and risk of ALS. Neurology. 2007; 69(15): 1508-14. 
16. Horner RD, Kamins KG, Feussner JR, Grambow SC, HoffLindquist J, Harati $Y$, et al. Occurrence of amyotrophic lateral sclerosis among Gulf War veterans. Neurology . 2003; 61(6): 742-9.

17. Ellis CM, Simmons A. Diffusion tensor MRI assesses corticospinhal tract damage in ALS. Neurology. 1999; 53: 1051-1058.

18. Brooks Br. El Escorial revisited: revised criteria for the diagnosis of amyotrophic lateral sclerosis. Amyotrophic lateral sclera other motor neuron disord. 2000; 1: 293-299.

19. Jacob S. Diffusion tensor imaging for long-term follow-up of corticospinhal tract degeneration in amyotrophic lateral sclerosis. Neuroradiology. 2003; 45: 598-600.

20. Grahan JM. Diffusion tensor imaging for the assessment of upper motor neuron integrity in ALS. Neurology. 2004; 63: 2111-2119.

21. Rocha AJ, Oliveira ASB. Detection of corticospinhal tract compromise in amyotrophic lateral sclerosis with brain MR Imaging: Relevance of the T1-Weighted spin-echo magnetization transfer contrast sequence. AJNR Am J Neuroradiol. 2004; 25: 1509-1515.

22. Sach M, Winkler G. Diffusion tensor MRI of early upper motor neuron involvement in amyotrophic lateral sclerosis. 2004; 127: 340-350

23. Oliveira ASB, Pereira RDB. Amyotrophic Lateral Sclerosis Three Letters that change the people's Life For Ever. Arq. Neuropsiquiatr. 2009; 67(3A): 750-82

24. Mitsumoto $H$, Rabkin JG. Palliative care for patients with amyotrophic lateral sclerosis: "prepare for the worst and hope for the best". JAMA: the journal of the American Medical Association. 2007; 298(2): 207-16.

25. Faria DC, Fávero FM, Fontes SV, Quadros AAJ, Oliveira ASB. Perfil clínico de pacientes com doença do neurônio motor no ambulatório da Unifesp. Rev Neurocienc.2008; 16(3): 189-93.

26. Forbes R.B.; Colville S.; Cran G.W.; Swingler R.J. Unexpected decline in survival from amyotrophic lateral sclerosis/motor neurone disease. J. Neurol. Neurosurg. Psychiatry 2004; 75: 1753-1755.

27. Matos SE, Conde MTRP, Fávero FM, Taniguchi M, Quadros AAJ, Fontes SV, Oliveira ASB. Mortality rates due to amyotrophic lateral sclerosis in São Paulo City from 2002 to 2006. Arq Neuropsiquiatr. 2011; 69 (6): 861-866

28. Lima J. M. B., Mesquita N., Duro L. A. A., Furtado A. B. Epidemiological aspects of amyotrophic lateral sclerosis in Rio de Janeiro city. Rev Brasileira de Neurologia 1983; 19(3): 75-78.

29. Dietrich-Neto F., Callegaro D., Dias-Tasta E., Silva H. A., Ferraz M. E., Lima J. M. B., Oliveira A. S. B. Amyotrophic Lateral Sclerosis in Brazil: 1998 national survey. Arq neuropsiquiatr. 2000: 58(3-A): 607-615.

30. Castro-Costa C. et al. Amyotrophic Lateral Sclerosis: Clinical Analysis Of 78 Cases from Fortaleza (Northeastern Brazil). Arq Neuropsiquiatr. 1999; 57(3-B): 761-774.
31. Moraes L, Goldbaum M, Silva HCA, Callegaro D. Incidence rate of amyotrophic lateral sclerosis (ALS) in Sao Paulo city, Brazil, 1991-1997. Arq Neuropsiquiatr. 1998; 56(Supl 1): 343.

32. Werneck LC, Bezerra R, Silveira Neto O, Scola RH. A clinical epidemiological study of 251 cases of amyotrophic lateral sclerosis in the south of Brazil. Arq. Neuro-Psiquiatr. 2007; 65(2A): 189-95

33. SEADE. Fundação Sistema Estadual de Análise de Dados. População e estatísticas de saúde. São Paulo; 2004. [acesso em 12 de fev 2008]. Disponível em: http://www.seade.gov.br/ produtos/idr/dem/dem_pop_04.xls

34. Turner MR, Brockington A, Scarber J, Hollinger $H$, Marsden R, Shaw PJ, Talbot K. Pattern of spread and prognosis in lower limb-onset ALS. Amyotrophic Lateral Scler.2010; 11(4): 369-73.

35. Kõrner S, Kollewe K, Fahlbusch M, Zapf A, Dengler R, Krampfl $K$, Petri S. Onset and spread patternsof upper and lower motor neuron symptons in amyotrophic lateral sclerosis. Muscle Nerve.2011; 43(5): 636-42.

36. Chiò A, Calvo A, Moglia C, Mazzini L, Mora G, Parals study group. Phenotypic heterogeneity of amyotrophic lateral sclerosis: a population based study. J. Neurol Neurosurg Psychiatry. 2011; 82(7): $740-6$

\section{Comment on this article:}

\section{(f) $B$ in $8+S P$}

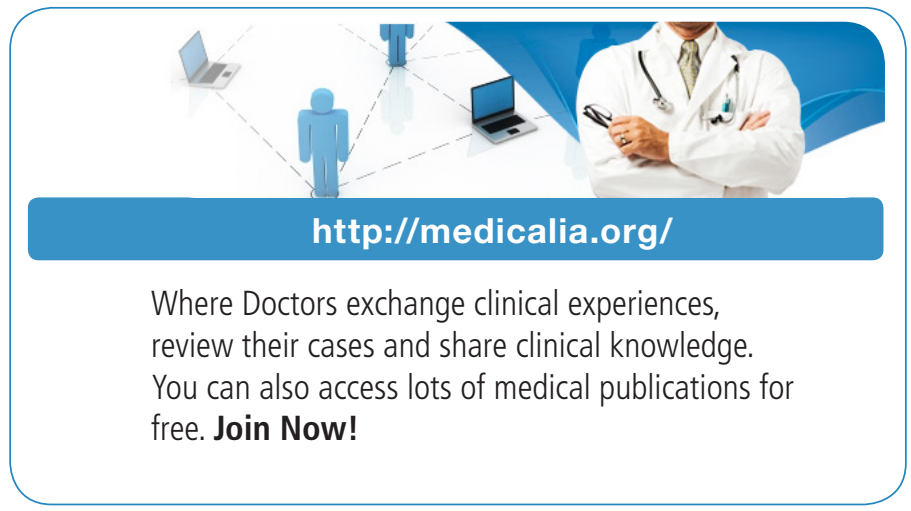

Publish with iMedPub

\section{http://www.imed.pub}

International Archives of Medicine is an open access journal publishing articles encompassing all aspects of medical science and clinical practice. IAM is considered a megajournal with independent sections on all areas of medicine. IAM is a really international journal with authors and board members from all around the world. The journal is widely indexed and classified Q1 in category Medicine. 